\title{
VERDADES PECULIARES
}

\author{
Carlos Chumbes Rojas, Lic. \\ Universidad Peruana Unión \\ Pastor Principal de la Iglesia de Villa Unión \\ carloschumbes@teología.edu.pe
}

Fecha de recepción: Noviembre 2014.

Fecha de aceptación y versión final: Diciembre 2014.

Texto base: Apocalipsis 14:6-13

Propósito general: Consagración

Palabra clave: Verdades

\section{Introducción:}

Saludo: Un cariñoso saludo para el pueblo de Dios, y bienvenidos para estudiar las verdades distintivas.

Proposición: A la luz de este estudio, identificaremos el mensaje divino para nuestra generación, el que debemos conocer, creer, vivir y predicar antes del desenlace del Conflicto Cósmico.

Disparador: 42,000 hombres fueron degollados por no saber hablar bien una palabra. Jueces 12:16. La palabra "shibolet", "espiga”; o "río", "curso de agua" que los efraimitas no supieron pronunciar, y decían "sibolet"

${ }^{1}$ SHIBOLET = "espiga"; o "río", "curso de agua". En el dialecto local de los efrainitas, el fonema lingual sibilante $\mathbf{s}$ tomó el lugar de fonema 
Si por no saber pronunciar una palabra 42,000 hombres fueron degollados; ise imaginan cuántos profesos adventistas, por no saber a ciencia cierta las verdades peculiares del pueblo de Dios, pueden terminar perdidos y perdiendo a otros que los oyen y los imitan?

El pueblo adventista del séptimo día, desde su nacimiento, tiene verdades peculiares que, de ser olvidadas, perdería su identidad de "linaje escogido", "real sacerdocio", "nación santa", "pueblo adquirido" (1 P 2:9).

Una reveladora cita de Elena G. de White identifica estas verdades distintivas del pueblo de Dios:

Cita: El tiempo transcurrido en 1844 fue un periodo de grandes eventos, que abrió ante nuestros ojos asombrados la purificación del Santuario que se llevaba a cabo en el cielo, y tuvo una decidida relación con el pueblo Dios sobre la tierra; [también con] los mensajes del primero y segundo ángeles y con el tercero, y desplegó el estandarte en el cual estaba inscrito: "Los mandamientos de Dios y la fe de Jesús". Uno de los hitos de este mensaje fue el templo de Dios, visto en el cielo por su pueblo amante de la verdad, y el arca que contenía la ley de Dios. La luz del día de reposo del cuarto mandamiento resplandeció con sus fuertes rayos en el camino de los transgresores de la ley divina. La no inmortalidad de los malvados es un antiguo hito. No puedo recordar nada más que pueda colocarse bajo el título de los antiguos hitos. - Counsels to Writers and Editors, 30-31 (1889). \{EUD 42.4\} (EUD 43).

Pregunta de transición: ¿Cuáles son esas verdades peculiares que el pueblo de Dios debe de conocer a fon-

palatal sibilante sh al comienzo de las palabras. 
do, obedecerlas y predicarlas sin ediciones personales y generacionales?

Oración de transición: Prestemos mucha atención para que no nos suceda como a los efrainitas que pretendieron saber lo que, en realidad, no sabían bien y por eso fueron degollados 42 mil de ellos.

\section{I.- La purificación del Santuario celestial y el ministerio sacerdotal de Cristo.}

Lección: Conocer la verdad de la purificación del Santuario celestial y el Sacerdocio celestial de Cristo, es conocer los alcances del plan de salvación y su efectividad para redimirnos.

Texto prueba: He 9:22-24; 4:14-16.

- Hay realidades espirituales que se deben tener muy presentes del conflicto cósmico.

- El pecado se originó en el cielo (Ap 12:7-9) y, como parte del exterminio de este (Mal 4:1), Dios ha provisto la purificación de su Santuario celestial (Dn 8:14).

- Comprender esta realidad espiritual es decisiva para la redención de los creyentes.

- Esta verdad comprendida nos hace amar más a Cristo y a su santa voluntad.

- Nos hace conscientes de que la salvación no es solo un acto divino aislado, sino un conjunto de actos, un proceso bien elaborado y efectuado por el mismo Señor.

- Hay verdades esenciales que debemos conocer respecto del Santuario celestial: 1) Cristo es el Sumo 
Sacerdote; 2) Cristo ministra con su propia sangre; 3) Cristo intercede por los creyentes arrepentidos; 4) Cristo purifica el Santuario y la vida de los creyentes que lo buscan; 5) Cristo saldrá del Santuario para venir al mundo en gloria de su Padre; 6) Cristo no ha revelado el tiempo en que termine su ministerio en el Santuario celestial.

- Su ministerio sacerdotal en el Santuario celestial es el período más largo en el plan de salvación.

- Todo creyente será victorioso en su lucha contra el pecado si accede al Sacerdote divino que está en el Santuario celestial (He 4:14-16).

Ilustración: El chofer de un hombre rico sacó el auto de su patrón sin su permiso. Como no lo estacionó en la cochera acostumbrada sino en la calle. Al regresar de la gestión que hizo descubrió que el parachoques posterior estaba abollado. Asustado fue a su amigo planchador y pintor de autos, para que lo planchara y lo pintara. El planchador, al ver a su amigo en aprietos por esta situación, lo tranquilizó haciéndole saber que hay una sola forma de resolver este problema, y era que tenía que comprar un parachoques nuevo y que la casa que comercializa estos autos, vende esta accesorios listos para ser instalados. Esto le produjo esperanza y sosiego a tan atribulado chofer.

Aplicación: Con las horrendas manchas condenatorias y destructoras del pecado acudamos a Cristo en sincero arrepentimiento, ya que él nos dará un corazón limpio y un espíritu recto para sentirnos como nuevos. 


\section{II.- El triple mensaje angélico: vigencia y pro- clamación.}

Lección: Todo adventista que se precie de serlo a cabalidad conoce estos mensajes, los cree, los honra y los proclama.

Texto prueba: Apocalipsis 14:6-13.

- Cada mensaje angélico es consecutivo y tiene que ser asimilado con prontitud.

- Un vistazo rápido de estos nos hace notar su importancia, urgencia, su alcance y obliga a cada uno tomar una postura definida.

- El $1^{\circ}$ ángel: Invoca a los hombres para dejar su posición antagónica y descuidada contra Dios y demanda que se lo reconozca como el Creador y Sustentador del mundo, y que se le dé gloria y honor. Nos dice: RECONOCE Y ADORA A DIOS.

- El $2^{\circ}$ ángel: Acredita la inevitable caída de la tramposa y milenaria Babilonia, que ya no puede esconder más sus mentiras que, como casa que se construyó sobre la arena, se desmorona ante las demandas divinas. Nos dice: BABILONIA CAERÁ CON SUS MENTIRAS Y MALDADES.

- El $3^{\circ}$ ángel: Advierte explícitamente a todo aquel que se sienta seducido a formar parte de los engaños de la bestia. Los castigos que le esperan a la "bestia y a su imagen" son por demás insufribles y de consecuencia eternas. Nos dice: No te unas a LA BESTÍA, SERÁ TERRIBLEMENTE CASTIGADA, ALÉJATE DE ELLA. 
Ilustración: Una educada dama le decía a un colportor que le presentaba el libro "Conflicto Cósmico". - Yo no me meto con nadie y a nadie hago daño, y cada vez que puedo ayudo a los que realmente necesitan. Supongo que Dios ha de considerar eso para que me salve. No creo que él sea tan malo que por no haber estado siempre en su Iglesia, me vaya a mandar al infierno.

Aplicación: Adorar a Dios, como Él lo demanda es el pasaporte y visa de que hemos sido redimidos en Cristo, y es nuestra seguridad contra los engaños seductores de la gran ramera y de las rameritas.

\section{III.- Vida eterna solo por la fe en Jesucristo.}

Lección: La vida eterna es un don de Dios, y es de su exclusiva potestad; obtenido por Cristo en la cruz y brindada a todo pecador arrepentido que le cree y acepta como Salvador y Señor de su vida.

Texto prueba: Juan 5:24, 25; Hechos 4:12.

- Realidades contundentes: "Por medio de un solo hombre el pecado entró en el mundo, y por medio del pecado entró la muerte; fue así como la muerte pasó a toda la humanidad, porque todos pecaron". (Ro 5:12 NVI)

- "Porque la paga del pecado es muerte, mientras que la dádiva de Dios es vida eterna en Cristo Jesús, nuestro Señor". (Ro 6:23 NVI).

- "Ciertamente les aseguro que el que oye mi palabra y cree al que me envió, tiene vida eterna y no 
será juzgado, sino que ha pasado de la muerte a la vida”. (Jn 5:24 NVI).

- La vida eterna no es algo inherente en el hombre pecador.

- No es que por haber vivido en este mundo siendo bueno, o por haber sufrido mucho es que se tiene derecho a la vida eterna.

- La verdad es que por ser pecadores por naturaleza, pesa sobre nosotros condenación eterna.

- Solo tenemos vida eterna en Cristo, esta es la única forma de tenerla. No hay ninguna otra forma de salvación, y no hay diversas formas de obtenerla. (Mt 1:21; Hch 10:43; 1 Ti 2:5).

- Ilustración: Satanás ha inventado mitos sobre la muerte que muchos incautos prefieren creer. Ideas como "vida después de la muerte", "el desdoblamiento astral", "el karma", etc. Estos engaños ya han pasado la barrera de lo mítico o misterioso, ya no solo es un asunto de brujos, chamanes o espiritistas; también hay científicos que están asegurando de que "la física cuántica demuestra que hay vida después de la muerte". Uno de ellos es un médico, el Dr. Robert Lanza, profesor de la Escuela de Medicina de la Universidad Wake Forest de Carolina del Norte ${ }^{2}$

Aplicación: Adán y Eva perdieron el hogar edénico por creerle a la serpiente; Cristo ha hecho posible la recuperación del hogar celestial por creerle a Dios.

${ }^{2}$ http://actualidad.rt.com/ciencias/view/111416-fisica-cuantica-vida-despues-muerte 


\section{Conclusiones:}

Resumen: tres verdades peculiares que como pueblo de Dios debemos tener muy presente, justo antes del retorno de Cristo:

1.- La purificación del Santuario celestial y el ministerio sacerdotal de Cristo.

2.- La vigencia y proclamación del mensaje de los tres ángeles.

3.- La vida eterna solo es posible por Cristo Jesús.

Aplicación: Acudamos a Cristo en busca de su Sacerdocio, atendamos y prediquemos el triple mensaje angélico y presentemos solo a Cristo como el único y suficiente Salvador y dador de vida eterna.

Llamado: Hoy tenemos, una vez más, la gran oportunidad de definir nuestra posición en los días previos a los eventos finales del conflicto cósmico.

Si estás convencido de que estas son las verdades distintivas del pueblo de Dios de hoy, y quieres aprovechar el Ministerio Sacerdotal de Cristo en el Santuario celestial; creer, vivir y predicar el triple mensaje angelical y confirmar tu salvación solo en Cristo Jesús. Te invito a venir para que te acerques a esta plataforma, y así juntos nos renovemos en la entrega total de nuestro corazón y vida a Dios y a sus verdades distintivas.

Ven que Dios espera de ti una conversión plena y una entrega de todo tu ser, además de tus facultades y talentos.

Oremos, creamos y hagamos 


\section{GUÍA DE TRANSLITERACIÓN PARA CARACTERES HEBREOS Y GRIEGOS}

Consonantes y vocales equivalentes para los caracteres hebreos:

\begin{tabular}{|c|c|c|c|c|}
\hline$\kappa=$, & $\eta=w$ & $כ=k$ & $y=`$ & \urcorner$=r$ \\
\hline ב ב $=b$ & $i=z$ & $\zeta=l$ & $פ=p$ & $\dot{w}=\dot{s}$ \\
\hline$\lambda \lambda=g$ & $\pi=j$ & $\boldsymbol{y}=m$ & $פ=f$ & $\ddot{w}=s h$ \\
\hline$ד\urcorner=d$ & $v=t$ & $\jmath=n$ & $צ=t s$ & $\Re=t$ \\
\hline$\pi=h$ &,$=y$ & $0=s$ & $p=q$ & $\Omega=t h$ \\
\hline$=a$ & $=e$ & $=i$ & $=0$ & $\vartheta=\hat{u}$ \\
\hline$=\bar{a}$ & $\therefore=\hat{e}$ & $?=\hat{\imath}$ & $=0$ & $=u$ \\
\hline$=a$ & $=e$ & & $\cdot \dot{j}=\hat{o}$ & \\
\hline
\end{tabular}

Consonantes y vocales equivalentes para los caracteres griegos:

\begin{tabular}{|l|l|l|l|l|}
\hline$\alpha=a$ & $\eta=\bar{e}$ & $v=n$ & $\tau=t$ & $\dot{\tau}=h$ \\
$\beta=b$ & $\theta=t h$ & $\xi=x$ & $v=y$ & $\dot{\rho}=r h$ \\
$\gamma=g$ & $\imath=i$ & $\mathrm{o}=o$ & $\varphi=p h$ & $\gamma \chi=n j$ \\
$\delta=d$ & $\kappa=k$ & $\pi=p$ & $\chi=c h$ & $\gamma \xi=n x$ \\
$\varepsilon=e$ & $\lambda=l$ & $\rho=r$ & $\psi=p s$ & $\gamma \kappa=n k$ \\
$\zeta=z$ & $\mu=m$ & $\sigma \varsigma=s$ & $\omega=\bar{o}$ & $\gamma \gamma=n g$ \\
\hline
\end{tabular}

